\title{
Bacterial metabolism of side-chain-fluorinated aromatics: unproductive meta-cleavage of 3-trifluoromethylcatechol
}

\author{
Karl-Heinrich Engesser ${ }^{1}$, Miguel Angel Rubio ${ }^{2}$, and Hans-Joachim Knackmuss ${ }^{1}$ \\ ${ }^{1}$ Institut für Mikrobiologie der Universität Stuttgart, Azenbergstrasse 18, D-7000 Stuttgart-1, Federal Republic of Germany \\ ${ }^{2}$ Technische Universität Hamburg-Harburg, Abteilung für Gewässerreinigungstechnik, D-2100 Hamburg 90, Federal Republic \\ of Germany
}

Received 3 July 1989/Accepted 9 October 1989

\begin{abstract}
Summary. Sixteen bacterial strains capable of degrading alkylbenzenes and alkylphenols were directly isolated from soil and water. The degradation pathways are discussed. Alkylcatechols are almost exclusively cleaved via meta-ring fission. Meta-cleavage of 3-trifluoromethyl-(TFM)-catechol was observed with all strains at different rates although the reaction rates compared to catechol as a substrate varied considerably. All 2hydroxy-6-oxohepta-2,4-dienoic acid hydrolases investigated showed strong binding of 7,7,7-trifluoro-2-hydroxy-6-oxohepta-2,4-dienoic acid, the ring fission product of 3-TFM-catechol. Turnover rates, however, were negligible indicating this compound to be a general dead-end metabolite during metabolism of TFM-substituted compounds via meta-cleavage pathways.
\end{abstract}

\section{Introduction}

Aromatics carrying the trifluoromethyl (TFM)group as a substituent are produced for agricultural (Kühle and Klauke 1977; Newbold 1979; Corbett et al. 1984; Mazzola et al. 1984; Schiemann and Cornils 1969), pharmaceutical (Filler 1979; Schiemann and Cornils 1969) and industrial applications (Lusby et al. 1980; Harms 1979; Schiemann and Cornils 1969; Wolfrum 1979). In contrast to the trichloromethyl-group the TFMgroup is, in general, resistant to hydrolysis and can also be assumed to be biochemically inert (Quistad and Mulholland 1983).

The xenobiotic nature of the TFM-group (Knackmuss 1981) is responsible for slow and incomplete degradation of this class of compounds in laboratory- and ecosystems (Lombards 1979;

Offprint requests to: $\mathrm{K}$.-H. Engesser
Jungclaus et al. 1978; Kussmaul 1978; Engesser et al. 1988a, b). On the other hand the TFM-group constitutes a real challenge for the evolution of new enzymes which are able to cope with this structural element. Although it resembles a methyl group in terms of bulkiness, it is totally different as far as the electronic characteristics are concerned (Engesser et al. 1988a).

Earlier investigations with pseudomonads and a Rhodococcus strain (Engesser et al. 1988a, b) demonstrated that side-chain fluorination had a severe impact on the metabolism of methylbenzoates. During co-metabolism of 3- and 4-TFMbenzoate via different degradation pathways a common dead-end metabolite, 7,7,7-trifluoro-2hydroxy-6-oxohepta-2,4-dienoic acid (7-TFHOD) was accumulated from TFM-catechols (Fig. 1).

Following the principles of bacterial degradation of alkyl-substituted aromatics, many TFMsubstituted analogues (Fig. 2) could be similarly metabolized to 3-TFM-catechol. As the prevalent mode of ring fission of 3-alkylcatechols is metafission, i.e. cleavage of the ring between $\mathrm{C} 2$ and $\mathrm{C} 3$ of the catechol moiety, 7-TFHOD can be postulated to be the main metabolite from 3-TFM catechol with biochemical and ecological significance.

The present study was undertaken to clarify the catalytic efficiency of 2-hydroxy-6-oxohepta2,4-dienoic acid (HOD) hydrolases from different soil and water bacteria with 7-TFHOD as a substrate. The question which remained to be answered was whether 7-TFHOD is generally resistant against enzymatic attack by hydrolases. For this purpose it was essential to show firstly that all the isolated bacteria are different from each other and secondly, that metapyrocatechase and semialdehyde-hydrolase are key enzymes of alkylarene degradation in these organisms. 
Cometabolic action of peripheric sequences of aromatics degradation on TFM compounds

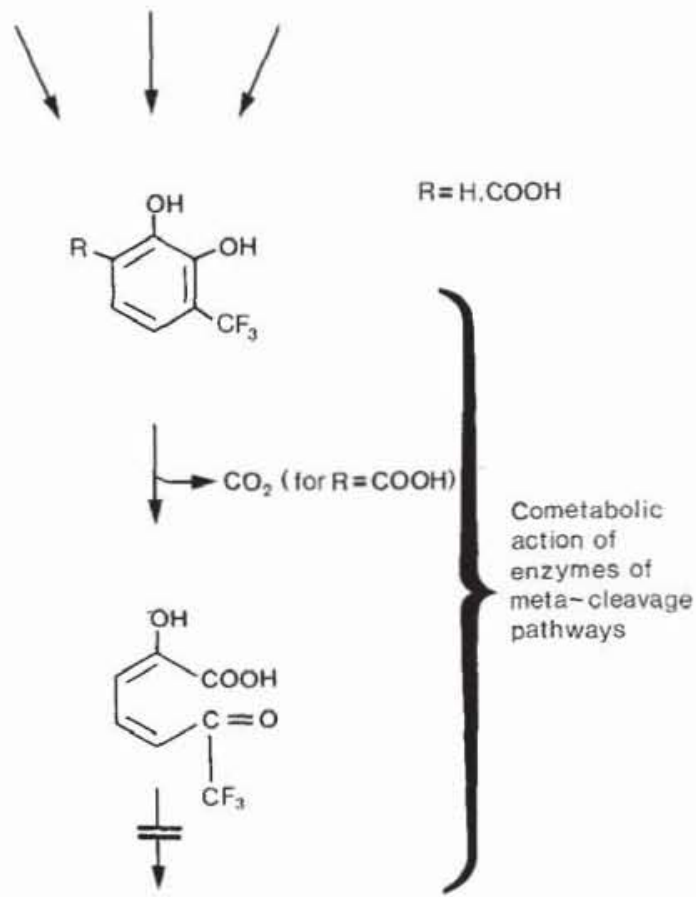

Fig. 1. Co-metabolic transformation of trifluoromethyl (TFM)-substituted aromatics to the dead-end product 2-hydroxy-6-oxo-7,7,7-trifluorohepta-2,4-dienoate

\section{Materials and methods}

Isolation, maintenance and cultivation of microorganisms. The bacterial strains were isolated from inocula derived from a mixture of many different soil and sewage samples collected in the region of Göttingen and the Harz mountains (FRG). The media used for isolation and purification were described by Dorn et al. (1974). Volatile carbon sources were supplied through the vapour phase with the exception of $o$-cresol.

The strains were directly isolated on plates without previous liquid cultivation in order not to isolate siblings. They were selected according to differences in visually detectable properties and checked for purity on nutrient broth agar. Cells were grown at $30^{\circ} \mathrm{C}$ in $500-$ or $3000-\mathrm{ml}$ sealed erlenmeyer flasks with baffles containing 50 or $500 \mathrm{ml}$ of growth medium by shaking on a rotary shaker at $150 \mathrm{rpm}$. Alkylbenzenes were introduced with a syringe into a side-arm equipped with a septum.

Preparation of washed suspensions of bacteria. Organisms were harvested by centrifugation $\left(3000 \mathrm{~g}\right.$ for $20 \mathrm{~min}$ at $28^{\circ} \mathrm{C}$ ) washed once with potassium-phosphate buffer $(50 \mathrm{mM}, \mathrm{pH}$ 7.4) and resuspended in the same buffer.

Preparation of extracts. Washed suspensions were disrupted by passage through a French pressure cell (Aminco, Md, USA; $140 \mathrm{MPa}, 0^{\circ} \mathrm{C}$ ). To remove cell debris the lysate was centrifuged at $100000 \mathrm{~g}$ for $60 \mathrm{~min}$ at $4^{\circ} \mathrm{C}$. The supernatant was termed crude extract.

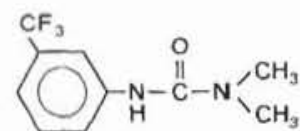

(a)
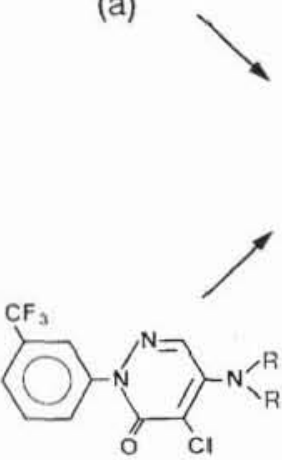

(c)

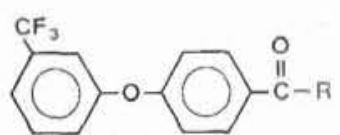

(b)

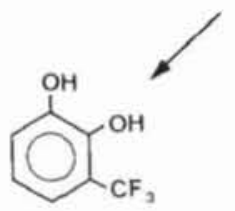

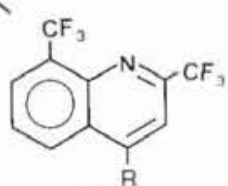

(d)
Fig. 2. Hypothetical scheme of biotransformation reaction of Fluometuron (a), pyrethroids (b), 5AN 6706 (c) and Mefloquine (d) to the central intermediate 3-trifluoromethylcatechol

Protein determination. The protein content of extracts was determined by the method of Bradford (1976).

Characterization of bacteria. All phenotypic markers were tested according to Gerhardt et al. (1981). The potential of using nitrate as an electron acceptor was investigated with an intermediate transfer of aerobically grown cells to a semianaerobic step, after which truly anaerobic conditions were established. Additionally the isopropylbenzene (IRB) strains isolated with isopropylbenzene were analysed using the API 20 NE test (Api, Bio-Merieux, Nürtingen, FRG). For estimation of the substrate spectrum of the strains, the carbon sources were supplied in the agar at $3 \mathrm{mM}$ with the exception of methanol and the phenols $(2 \mathrm{mM})$. Volatile substrates were supplied in the vapour phase, the plates being incubated at $30^{\circ} \mathrm{C}$ in gas-tight containers.

Enzyme activities in whole cells. Activities of initial enzymes of alkylarene oxygenation as well as ring fission enzymes were determined using an oxygen electrode. Insoluble substrates were solubilized by use of dimethyl formamide or dimethylsulphoxide. Stock solutions $(40 \mu \mathrm{l} ; 40 \mathrm{mM})$ were added to $4 \mathrm{ml}$

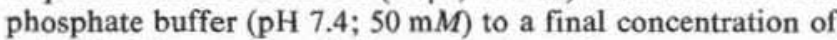
$0.4 \mathrm{mM}$. The stock solutions of phenolics were prepared freshly before use as they polymerized to black products. Previous experiments had shown that the solubilizing agents would not influence oxygen utpake. Activities were corrected for endogenous respiration rates which never exceeded $20 \%$ of the final uptake rate.

Enzyme activities in cell extracts. Ring-fission enzymes and semialdehyde-metabolizing enzymes were estimated photometrically in phosphate buffer $(50 \mathrm{mM} ; \mathrm{pH} 7.4)$ using extinction coefficients as described elsewhere (Engesser et al. 1988a, b). In cases where strong activity of HOD hydrolases made photometric detection of ring-fission enzymes impossible, an oxygen electrode was used. Nicotineamide adenine dinucleotide (NAD)-dependent 1,2-dihydro-1,2-dihydroxybenzoate-dehydrogenase was assayed as described previously (Engesser et al. $1988 \mathrm{a})$ as well as gentisic acid 1,2-dioxygenase, protocatechuate-3,4 and 4,5-dioxygenase (Wang et al. 1987; Whittaker et al. 1984; Dagley et al. 1968). 


\section{Results}

\section{Isolation of microorganisms}

Soil and river water samples from many different locations in Göttingen and the Harz mountains were used to select bacteria growing with alkylbenzenes and alkylphenols as sole carbon sources. The moistened soil samples were mixed and perfused with phosphate buffer several times. After concentration by sterile centrifugation of the soil supernatant in order to avoid contamination with laboratory strains, $0.1 \mathrm{ml}$ of cell suspension was spread on mineral agar plates which were incubated in gas-tight glass containers. Hydrocarbons were supplied via the vapour phase.

After 2 weeks, 16 hydrocarbon-utilizing strains were directly isolated by repeatedly streaking different single, actively growing colonies on minimal agar plates incubated in a hydrocarbon atmosphere. The isolates were checked for purity on nutrient broth agar plates. They were designated according to the substrate used for their selection as IRB 110 to 140 (isopropylbenzene), ELB 110 to 140 (ethylbenzene) and MLB 110 to 140 (methylbenzene). Bacteria utilizing 2-methylphenol were termed MLP 110 to 140.

\section{Growth of microorganisms}

All strains could grow in liquid culture, as described in Materials and methods, with the respective hydrocarbon as sole carbon and energy source. No growth factors were required.

\section{Characterization of isolates (only the most important data are given)}

The MLP strains were classified as belonging to the genus Pseudomonas. The strains are all motile rods with rounded ends, strictly aerobic, Gramnegative, oxidase- and catalase-positive. The same classification as for Pseudomonas sp. applied to IRB 110, 120 and 130. According to analysis of ubiquinones, polyamines, soluble proteins and whole-cell lipopolysaccharides as well as DNA: DNA hybridization studies and API 20 NE tests, IRB 110,120 and 130 were identified as $P$. fluorescens (personal communication of G. Auling, Department of Microbiology, University of Hannover; results will be published elsewhere). Only IRB 110 and 130 can use nitrate as an electron acceptor. Strain IRB 140 differed markedly from the other IRB strains in that it was Gram-variable although the $\mathrm{KOH}$ reaction as well as the aminopeptidase test indicated a cell wall of the Gramnegative type (Moaledj 1986). The coccoid cells were immobile, catalase-positive and oxidase-negative. Strain IRB 140 was tentatively classified as an Acinetobacter species, which is indicated also by the API 20 NE test.

Strains ELB 110, 130 and 140 are all Gramnegative, non-motile, oxidase- and catalase-positive rods which tended to be coccoid at the end of the logarithmic growth phase. They were lysed by $3 \% \mathrm{KOH}$ and showed aminopeptidase activity. Strains ELB 110,130 and 140 could tentatively be assigned to the genus Moraxella-like Acinetobacter group. Strain ELB 120 was very different from the other ELB strains. The cells were Grampositive, non-motile, catalase-positive, oxidasenegative, rod-shaped, often with swollen ends and frequently showed primary branching. For the present, ELB 120 may be classed within the family Mycobacteriaceae. This family includes genera such as Mycobacterium, Rhodococcus and Nocardia (Stackebrandt and Schleifer 1984).

The Gram-positive, immobile, oxidase-negative, catalase-positive, non-spore-forming MLB strains formed two morphological subgroups. Both were not lysed by $3 \% \mathrm{KOH}$. Strains MLB 110 and 120 exhibited a rod-coccus cycle, the rods showing primary branching. With strain MLB 110 , V-shaped structures could frequently be observed, which are typical for the genus Arthrobact$e r$. Both strains are likely to belong to the family Mycobacteriaceae. Strains MLB 130 and 140 did not show a complete rod-coccus cycle but were slightly pleomorphic with nearly no branching and there were no swollen ends. These two strains according to data not given, may belong to the genus Brevibacterium. The ortho-methylanilinedegrading Pseudomonas sp. JL1 has been described elsewhere (Latorre et al. 1984).

\section{Substrate utilization patterns}

Substrate utilization patterns of all strains were determined for further differentiation. The MLB strains used methylbenzene and the following relevant aromatic substrates as a carbon source: benzene, isopropylbenzene, isobutylbenzene, benzaldehyde, benzoate, 3- and 4-hydroxybenzoate, 3methoxybenzoate, phenol and 4-methylphenol. Whereas phthalate, ethylbenzene, 1,3-diisopropylbenzene and terephthalate were utilized by MLB 120 and 140 , both strains could be differentiated by the inability of MLB 140 to degrade 3-methyl- 
benzoate, 2-isopropylphenol, 3-methylphenol, 2phenylpropene, phenylethene and aniline which were utilized by MLB 120 . On the other hand MLB 140 degraded 1,4-diisopropylbenzene. Both MLB 110 and 130 grew in the presence of 3-methylphenol, but only MLB 110 utilized 3-methylbenzoate, 2-methylphenol, ethylbenzene, 2-phenylpropene and phenylethene.

All ELB strains grew on ethylbenzene, benzaldehyde, benzoate, 4-hydroxybenzoate, 3-methylbenzoate, benzene and methylbenzene. Strain ELB 120 was very versatile utilizing further substrates such as 3-hydroxybenzoate, 3-methoxybenzoate, terephthalate, 4-methylphenol, isopropylbenzene, diisopropylbenzene, which were not utilized by the other ELB strains. Additionally ELB 120 dissimilated phenol, 2-isopropyl-, and 3methylphenol. Strains ELB 110, 130 and 140 all utilized 4-isopropylbenzoate and 3-isopropyltoluene. Strain ELB 110 could be separated from ELB 130 by its inability to grow on phenol and 3-methylphenol. Strain ELB 130 could utilize phenol in contrast to ELB 140. Both strains were however quite similar.

The IRB strains all utilized 4-hydroxybenzoate, methylbenzene and ethylbenzene besides isopropylbenzene. In contrast to the other IRB strains, IRB 130 did not grow with benzaldehyde and benzoate. Strain IRB 140 is the only strain that grew with 3-hydroxybenzoate and 3-meth- oxybenzoate. Strains IRB 110 and 120 cannot be distinguished by means of a substrate utilization pattern (but IRB 110 utilizes nitrate as an electron acceptor).

All the MLP strains utilized benzaldehyde, benzoate, 3-hydroxybenzoate, 3-methylbenzoate, phenol, 3- and 4-methylphenol besides $o$-methylphenol. Strain MLP 130 differed from the rest of the MLP strains in its ability to utilize 3-hydroxybenzoate. Both MLP 120 and 140 used 4-isopropylbenzoate, benzene, methylbenzene and 3-isopropyltoluene as carbon sources and could not be differentiated by simple substrate-utilization patterns.

\section{Biochemical characteristics of the isolates}

Degradation of the side-chain produces benzoate which in turn is oxidatively transformed to catechol; alternatively the nucleus is dioxygenated leaving the side-chain intact. After growth of the isolates with the respective carbon sources used for isolation, oxygen uptake rates were measured with different aromatic compounds. The IRB strains oxygenated all three alkylbenzenes tested (Table 1). The rate of oxygenation was roughly dependent on the length of the side-chain with isopropylbenzene being the best substrate. Benzoate was only slightly oxygenated indicating that

Table 1. Oxygen uptake rates by whole cells of methylbenzene (MLB), ethylbenzene (ELB) and isopropylbenzene (IRB) strains grown with selective sustrates

\begin{tabular}{|c|c|c|c|c|c|c|c|c|c|c|c|c|}
\hline Strains & $\begin{array}{l}\text { MLB } \\
110\end{array}$ & $\begin{array}{l}\text { MLB } \\
120\end{array}$ & $\begin{array}{l}\text { MLB } \\
130\end{array}$ & $\begin{array}{l}\text { MLB } \\
140\end{array}$ & $\begin{array}{l}\text { ELB } \\
110\end{array}$ & $\begin{array}{l}\text { ELB } \\
120\end{array}$ & $\begin{array}{l}\text { ELB } \\
130\end{array}$ & $\begin{array}{l}\text { ELB } \\
140\end{array}$ & $\begin{array}{l}\text { IRB } \\
110\end{array}$ & $\begin{array}{l}\text { IRB } \\
120\end{array}$ & $\begin{array}{l}\text { IRB } \\
130\end{array}$ & $\begin{array}{l}\text { IRB } \\
140\end{array}$ \\
\hline $\begin{array}{l}\text { Substrate used for } \\
\text { isolation }\end{array}$ & \multirow{2}{*}{\multicolumn{2}{|c|}{ Methylbenzene }} & & & \multirow{2}{*}{\multicolumn{2}{|c|}{ Ethylbenzene }} & & & \multirow{2}{*}{\multicolumn{3}{|c|}{ Isopropylbenzene }} & \\
\hline Test substrate & & & & & & & & & & & & \\
\hline Isopropylbenzene & 75 & 50 & 80 & 50 & 50 & 120 & 90 & 40 & $\begin{array}{c}100 \\
(260)\end{array}$ & $\begin{array}{c}100 \\
(320)\end{array}$ & $\begin{array}{c}100 \\
(280)\end{array}$ & $\begin{array}{c}100 \\
(430)\end{array}$ \\
\hline Ethylbenzene & 110 & 100 & 110 & 100 & $\begin{array}{c}100 \\
(375)\end{array}$ & $\begin{array}{c}100 \\
(480)\end{array}$ & $\begin{array}{c}100 \\
(495)\end{array}$ & $\begin{array}{c}100 \\
(610)\end{array}$ & 100 & 65 & 90 & 85 \\
\hline Methylbenzene & $\begin{array}{c}100 \\
(750)\end{array}$ & $\begin{array}{c}100 \\
(660)\end{array}$ & $\begin{array}{c}100 \\
(150)\end{array}$ & $\begin{array}{c}100 \\
(360)\end{array}$ & 70 & 90 & 105 & 95 & 60 & 55 & 20 & 60 \\
\hline Benzene & 15 & 15 & 50 & 25 & 25 & n.d. & 20 & 5 & 35 & 40 & 10 & 20 \\
\hline $\begin{array}{l}\text { Trifluormethylben- } \\
\text { zene }\end{array}$ & 40 & 36 & 50 & 25 & 35 & 50 & 60 & 30 & 65 & 50 & 20 & 50 \\
\hline Benzoate & 10 & 20 & 15 & 20 & 5 & 10 & 60 & 5 & 6 & 5 & 0 & 10 \\
\hline $\begin{array}{l}\text { 4-Hydroxybenzoate } \\
\text { 2-Hydroxybenzoate }\end{array}$ & 10 & 20 & 0 & 10 & 5 & 4 & 0 & 5 & 0 & 5 & 0 & $\begin{array}{l}5 \\
5\end{array}$ \\
\hline & n.d. & n.d. & 10 & 20 & n.d. & n.d. & n.d. & n.d. & 0 & 5 & 0 & 5 \\
\hline
\end{tabular}

Relative rates are given as percentages of the reference substrate taken as $100 \%$. Activities in parentheses are expressed in $\mu \mathrm{l} \mathrm{O}_{2}$ consumed per hour per mg dry weight. Oxygen consumption was measured polarographically with an oxygen electrode (all results have been corrected for endogenous respiration, see Materials and methods). Uptake rates of 2- and 4-hydroxybenzoate never exceeded $20 \%$ of that of the reference substrates. n.d. $=$ not determined 
Table 2. Oxygen uptake rates by whole cells of 2-methylphenol (MLP) strains grown with the selection substrate 2-methylphenol

\begin{tabular}{|c|c|c|c|c|}
\hline Test substrate & MLP 110 & MLP 120 & MLP 130 & MLP 140 \\
\hline Phenol & $\begin{array}{c}100 \\
(540)\end{array}$ & $\begin{array}{c}100 \\
(930)\end{array}$ & $\begin{array}{c}100 \\
(525)\end{array}$ & $\begin{array}{c}100 \\
(450)\end{array}$ \\
\hline 2-Methylphenol & 100 & 110 & 85 & 95 \\
\hline 3-Methylphenol & 80 & 70 & 70 & 85 \\
\hline 4-Methylphenol & 95 & 90 & 65 & 70 \\
\hline 3-Trifluoromethylphenol & 30 & 20 & 17 & 20 \\
\hline 2-Chlorophenol & 55 & 55 & 55 & 40 \\
\hline 2-Nitrophenol & 15 & 25 & 25 & 30 \\
\hline 2-Isopropylphenol & 30 & 45 & 55 & 45 \\
\hline 2-Hydroxybenzoate & 0 & 5 & 5 & 0 \\
\hline 2-Hydroxybenzaldehyde & 80 & 110 & 90 & 80 \\
\hline
\end{tabular}

Relative rates are given as percentages of the reference substrate phenol (100\%). Activities in parentheses are expressed in $\mu \mathrm{l} \mathrm{O}_{2}$ consumed per hour per mg dry weight. Oxygen consumption was measured polarographically with an oxygen electrode. All values have been corrected for endogenous respiration (see Materials and methods)

isopropylbenzene is attacked primarily at the nucleus in IRB strains, the side-chain remaining intact.

High relative oxygen uptake rates with 3-isopropylcatechol were detected (data not shown), which suggests that isopropylbenzene is metabolized via 3-isopropylcatechol. The observation that 2-hydroxy-7-methyl-6-oxoocta-2,4-dienoate (7,7dimethyl-HOD) is the product of its cleavage is consistent with the suggestion that metabolism is via a catechol 2,3-oxygenase (Table 3). The generation of this compound could be followed spectrophotometrically. Isopropylbenzene-grown cells of IRB 110, 120 and 130 were resuspended in phosphate buffer and allowed to transform freshly added isopropylbenzene. In all cases, the resulting yellow products showed UV spectra with maxima at $\lambda=317-319 \mathrm{~nm},(\mathrm{pH} 2), 387-389 \mathrm{~nm}$ and $325-332 \mathrm{~nm}(\mathrm{pH} 7.4)$ and $395-397 \mathrm{~nm}(\mathrm{pH}$ 12).

Authentic 7,7-dimethyl-HOD prepared by action of metapyrocatechase of P. putida mt-2 on 3isopropylcatechol (Duggleby and Williams 1986) proved the structure proposed above $\left(\lambda_{\max }=328 \mathrm{~nm}\right.$ at $\mathrm{pH} 1,389 \mathrm{~nm}$ at $\mathrm{pH} 7.5$ and $397 \mathrm{~nm}$ at $\mathrm{pH}$ 12). 2-Hydroxy-7-methyl-6-oxoocta-2,4-dienoate could be cleaved by a hydrolase yielding isobutyrate and 2-oxopent-4-enoate. On the basis of similar enzyme patterns, it is suggested that a similar pathway for the catabolism of ethyl- and methylbenzene exists in the ELB and MLB strains. All the key enzymes were detected (see Tables 1 and 3).

According to known reactions of the classical methylphenol degradation pathway (Bayly and Wigmore 1973; Ribbons 1966) the MLP strains are likely to hydroxylate 2-methylphenol yielding 3-methylcatechol (Table 2). After ring cleavage (Table 3) by catechol-2,3-dioxygenase, HOD is cleaved to acetate and 2-oxopent-4-enoate. With the exception of MLB 110, 120 and 130, no significant catechol-1,2-dioxygenase activity (sp.act. 107,33 and 125 units respectively) could be detected in extracts of all 16 strains grown with the respective substrates used for isolation.

When the MLB, ELB and IRB strains were checked for protocatechuate-3,4- and 4,5-dioxygenase, gentisate-1,2-dioxygenase and 1,2-dihydro-1,2-dihydroxybenzoic acid (DHB) dehydrogenase, very low activities of the latter enzyme could be detected in MLB strains (data not shown). This clearly excludes the possibility of degradation of alkylbenzenes after side-chain oxygenation and again favours dioxygenation of the nucleus as the principal mode of initial attack in all of these strains.

\section{Metabolism of trifluoromethyl (TFM) benzene}

After growth on the respective carbon sources used for isolation, cells of IRB, ELB and MLB strains were centrifuged and resuspended in phosphate buffer, pH 7.4, to optical densities of 5-10. TFM-benzene was added and the flasks were kept gas-tight using silicone stoppers. The generation of a yellow compound was followed photometrically at the absorption maximum $(=385 \mathrm{~nm}$ at $\mathrm{pH}$ 7.4). In all cases the spectroscopic properties of the accumulated compound totally matched that of authentic 7-TFHOD (Engesser et al. 1988a, b). The yield of 7-TFHOD was time- and strain-de- 


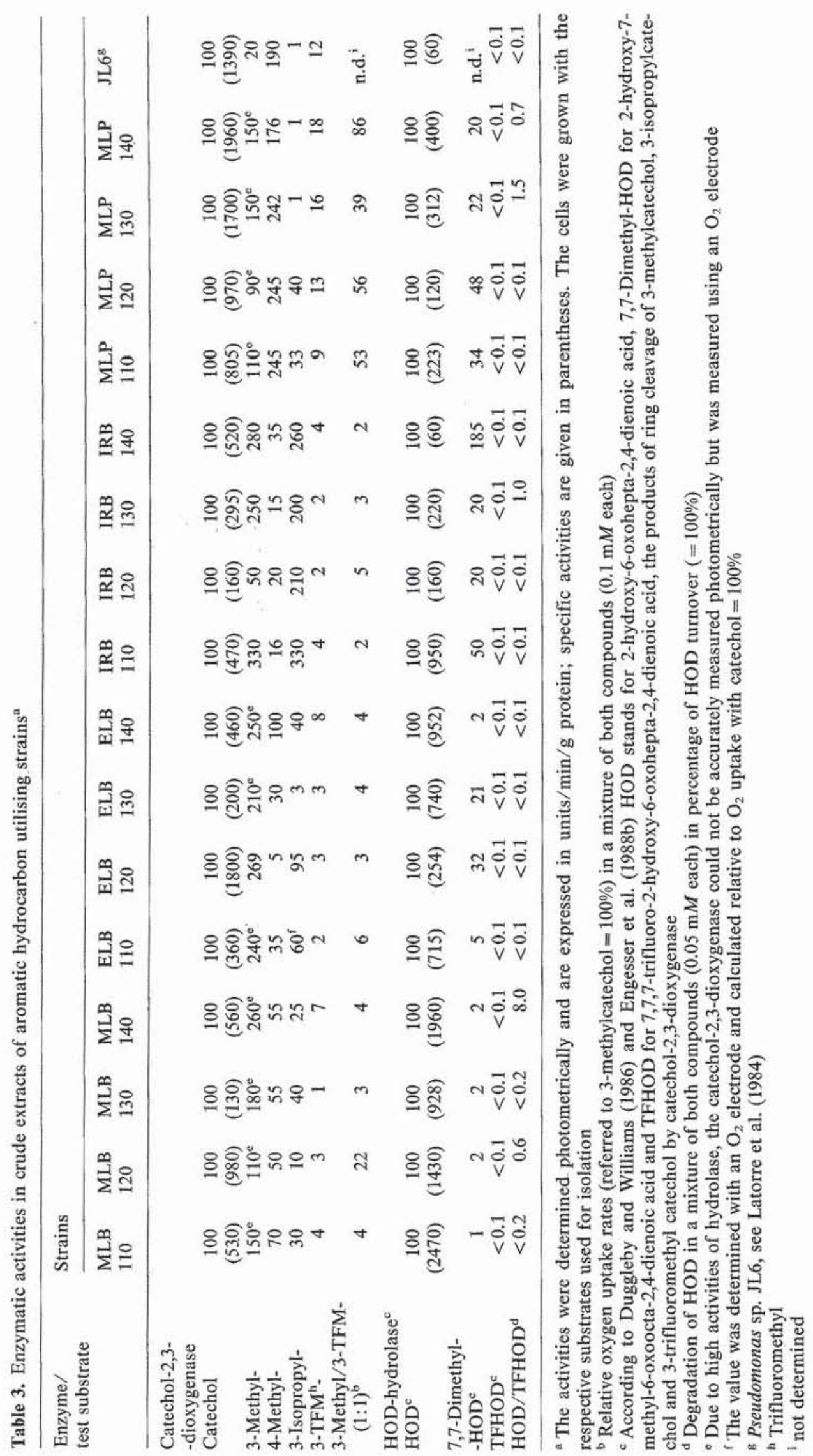


pendent, reaching a maximum of $95 \%$ with MLB 120 after $9 \mathrm{~h}$. With some strains additional metabolites were detected with HPLC. The structures of those compounds were not elucidated.

\section{Metabolism of 3-TFM-catechol and its ring-cleavage product}

All catechol-2,3-dioxygenases in crude extracts of all isolates grown on the respective carbon sources turned over with 3-trifluoromethyl (TFM)-catechol at rather low rates (Table 3). Competition between the substrates 3-methyland 3-TFM-catechol indicated strong binding of the latter substrate compared to catechol in all alkylbenzene-degrading isolates. The MLP strains however did not show preferential binding of the TFM-analogue over 3-methylcatechol. The catechol-2,3-dioxygenase from Pseudomonas sp. JL1 (Table 3) behaved like the enzymes from MLP strains. All hydrolases were unable to cleave 7,7,7trifluoro-hepta-2,4-dienoic acid (Table 3). Simple inhibition experiments revealed however, that this cannot be due to insufficient binding: with the exception of strain MLB 140, all hydrolases were strongly inhibited by the TFM-analogue during turnover of HOD or 7,7-dimethyl-HOD.

\section{Discussion}

Our knowledge concerning the behaviour of TFM-substituted aromatics in biological systems is still limited to TFM-aniline derivatives, which have been most intensively studied. For example 4-TFM-aniline has been shown to be carcinogenic (Thomson et al. 1983). The herbicide Trifluralin has been studied in many organisms and ecosystems (Erkog and Menzer 1985; Golab et al. 1979; Hamadi and Tewfik 1969; Hamdi et al. 1969; Lusby et al. 1980; Sloan and Camper 1981; Stralka and Camper 1981; Williams 1977; Zeyer and Kearney 1983). Fluorodifen, a TFM-group and nitrosubstituted biarylether has also been investigated to some extent (Shimabukuro et al. 1982; Tewfik and Hamdi 1975) as well as Fluometuron (Rickard and Camper 1978) and the lampricide 3-TFM-4-nitrophenol (Schultz et al. 1979). In neither case complete degradation of the TFMsubstituted compound was observed. Furthermore this metabolism, generally yielding a number of different products, was described to occur at low to very low rates. In general such compounds still contained the TFM-group and were tentatively identified by mass spectra. According to tracer experiments using ring-labelled TFM-substituted aromatics the cleavage of the nucleus was found to be a very rare event.

It was the intention of the present work to extend knowledge about biodegradation of TFMaromatics by using defined cultures in which relatively high co-metabolic activities can be induced by readily degradable structural analogues. In our previous investigations we described the dead-end nature of 7-TFHOD, a ring-cleavage product of the central intermediate 3-trifluoromethylcatechol in three defined strains. In the present communication we have extended our investigations on alkylaromatic-degrading strains isolated randomly from soil and water habitats (Engesser et al. 1988a, b). These were directly selected from agar plates without previous incubation in liquid culture. This procedure should avoid the isolation of siblings, which would reduce the possibility of generalizing the results gained. Indeed all strains were found to be more or less different from each other.

A very tentative identification of the strains has been given. The aim of this very rough taxonomic classification was solely to show that the strains are different from each other and that members of many different bacterial genera were investigated. This was essential in order to try a first and admittedly very short-range generalization of the fate of TFM-aromatics in the ecosystem. Accordingly, 7-TFHOD was clearly shown to be the principal persistent metabolite of degradation of TFM-aromatics if co-metabolized via 3TFM-catechol or a derivative of this compound as an intermediate.

Although the TFM-group can also exert inhibition of metabolism at other metabolic levels of aromatic catabolism, no HOD-hydrolase has been shown to metabolize 7-TFHOD to any measurable extent up to now. It is possible therefore that 7-TFHOD or analogues of this compound accumulate in the environment (Figs. 1, 2). In the presence of ammonium they could be transformed chemically by ring closure to pyridine derivatives (Engesser et al. 1988a). Besides a total ban of TFM-aromatics production, this problem could be circumvented in two ways. First fluoride can be liberated from 3-TFM-catechol non-enzymatically at normal $\mathrm{pH}$ and ambient temperatures (will be published elsewhere). Secondly we are at present trying to isolate mutants of cumate-degrading strains able to cope with 7-TFHOD, as all 
attempts to directly isolate strains degrading TFM-benzoates and TFM-phenols up to now have not proved successful.

Acknowledgements. We thank Professor Bayly for many helpful discussions during preparation of the manuscript and Dr. C. Braun for performing the anaerobic respiration assay with nitrate as electron acceptor. For skilled technical assistance we thank Miriam Bachmann, Simona Hartnack, Sylvia Schenke and Petra Schulte. The work was supported by a grant (IV A5FA 8972) from the Minister für Forschung und Wissenschaft des Landes Nordrhein-Westfalen.

\section{References}

Bayly RC, Wigmore GI (1973) Metabolism of phenol and cresols by mutants of Pseudomonas putida. J Bacteriol 113:1112-1120

Bradford MM (1976) A rapid and sensitive method for the quantitation of microgram quantities of protein utilizing the principle of protein-dye binding. Anal Biochem 72:248-254

Corbett JR, Wright K, Baillie AC (1984) The biochemical mode of action of pesticides, 2nd edn. Academic Press, London

Dagley S, Geary PJ, Wood JM (1968) The metabolism of protocatechuate by Pseudomonas testosteroni. Biochem J 109:559-568

Dorn E, Hellwig M, Reineke W, Knackmuss HJ (1974) Isolation and characterization of a 3-chlorobenzoate degrading pseudomonad. Arch Microbiol 99:61-70

Duggleby CJ, Williams PA (1986) Purification and some properties of the 2-hydroxy-6-oxohepta-2,4-dienoate hydrolase (2-hydroxymuconic semialdehyde hydrolase) encoded by the TOL plasmid pWWO from Pseudomonas putida $\mathrm{mt}-2$. J Gen Microbiol 132:717-726

Engesser KH, Cain RB, Knackmuss HJ (1988a) Bacterial metabolism of side chain fluorinated aromatics: cometabolism of 3-trifluoromethyl (TFM)-benzoate by Pseudomonas putida (arvilla) $\mathrm{mt}-2$ and Rhodococcus rubropertinctus $\mathrm{N}$ 657. Arch Microbiol 149:188-197

Engesser KH, Rubio MA, Knackmuss HJ (1988b) Bacterial metabolism of 4 -trifluoromethyl-(TFM)-benzoate by 4-isopropylbenzoate grown Pseudomonas putida JT strains. Arch Microbiol 149:198-206

Erkog FU, Menzer RE (1985) Metabolism of Trifluralin in rats. J Agric Food Chem 33:1061-1070

Filler R (1979) Fluorine containing drugs. In: Bank RE (ed) Organofluorine chemicals and their industrial applications. Society of Chemical Industry, Ellis Horwood Series in Industrial Chemistry, Ellis Horwood, Chichester, pp 122 153

Gerhardt P, Murray RGE, Costilow RN, Nester EW, Wood WA, Krieg NR, Philipps GB (1981) Manual of methods for general bacteriology. American Society for Microbiology, Washington D.C.

Golab T, Althaus WA, Wooten HL (1979) Fate of $\left[{ }^{14} \mathrm{C}\right]$ Trifluralin in soil. J. Agric Food Chem 27:163-179

Hamdi YA, Tewfik MS (1969) Decomposition of the herbicide Trifluralin by a pseudomonad. Acta Microbiol Pol Ser B $1: 83-84$

Hamdi YA, Zahran MK, Tewfik MS (1969) The breakdown of Trifluralin by soil microorganisms. PANS (Pest Artic New Summ) 15: 589-592
Harms W (1979) Reactive dyes containing fluorine. In: Bank RE (ed) Organofluorine chemicals and their industrial application. Society of Chemical Industry, Ellis Horwood Series in Industrial Chemistry, Ellis Horwood, Chichester, pp 188-207

Hutzinger O, Veerkamp W (1981) Xenobiotic chemicals with pollution potential. FEMS Symp 12:3-45

Jungclaus GA, Lopez-Avila V, Hites RA (1978) Organic compounds in an industrial wastewater. A case study of their environmental impact. Environ Sci Techol 12:88-96

Knackmuss HJ (1981) Degradation of halogenated and sulfonated hydrocarbons. FEMS Symp 12:189-212

Koskinen WC, Oliver JE, Kearney PC, McWhorter CG (1984) Effect of Trifluralin soil metabolites on cotton groth and yields. J Agric Food Chem 32:1246-1248

Kühle E, Klauke E (1977) Fluorinierte Isocyanate und deren Derivate als Zwischenprodukte für biologisch aktive Wirkstoffe. Angew Chem 89:797-804

Kussmaul H (1978) Behaviour of persistent organic compounds in bank-filtrated rhine-water. In: Hutzinger $\mathrm{O}$, Lelyveld $\mathrm{JH}$ van, Zoeteman $\mathrm{BCJ}$ (eds) Aquatic pollutions and biological effects. Proceedings of the Second International Symposium on aquatic pollutants, Amsterdam, 26.-28. 9. 1978. Pergamon Press, Oxford, pp 265-274

Latorre J, Reineke W, Knackmuss HJ (1984) Microbial metabolism of chloroanilines enhanced evolution by natural genetic exchange. Arch Microbiol 140:159-165

Lombards P (1979) FDA's chemical contaminants program: the search for the unrecognized pollutant. Ann NY Acad Sci 320:673-677

Lusby WR, Oliver JE, Kearney PC (1980) Metabolism of 2,4 dinitro-4-(trifluoromethyl)-benzeneamine by a Streptomyces. J Agric Food Chem 28:641-644

Mazzola EP, Borsetti AP, Page SW, Bristol DW (1984) Determination of pesticide residues in foods by fluorine- 19 . Fourier transform nuclear magnetic resonance spectroscopy. J Agric Food Chem Vol 32:1102-1103

Moaledj K (1986) Comparison of Gram-staining and alternate methods, $\mathrm{KOH}$ test and aminopeptidase activity in aquatic bacteria: their application to numerical taxonomy. J Microbiol Methods 5:303-310

Newbold GT (1979) Fluorine containing pesticides. In: Bank RE (ed) Organofluorine chemicals and their industrial applications. Society of Chemical Industry, Ellis Horwood Series in Industrial Chemistry, Ellis Horwood, Chichester, pp 169-187

Quistad GB, Mulholland KM (1983) Metabolism of p-chlorobenzotrifluoride by rats. J Agric Food Chem 31:585-589

Ribbons DW (1966) Metabolism of 0 -cresol by Pseudomonas aeruginosa strain T1. J Gen Microbiol 44:221-231

Rickard RW, Camper ND (1978) Degradation of fluometuron by Rhizoctonia solani. Pestic Biochem Physiol 9:183-189

Schiemann G, Cornils B (1969) Chemie und Technologie cyclischer Fluorverbindungen. Enke. Stuttgart

Schultz DP, Harman PD, Luhning CW (1979) Uptake, metabolism and elimination of the lampricide 3-trifluoromethyl-4-nitrophenol by largemouth bass (Micropterus salmoides). J Agric Food Chem Vol 27 No 2:328-331

Shimabukuro RH, Lamoureux GL, Frear DS (1982) Pesticide metabolism in plants and mechanisms. In: Matsamura F, Murti CR (eds) Biodegradation of pesticides. Plenum Press, New York, pp 21-66

Sloan ME, Camper NP (1981) Trifluralin effects on carrot callus tissue. Pestic Biochem Physiol 15:201-208

Stackebrandt E, Schleifer KH (1984) Molecular systematics of actinomycetes and related organisms. In: L. Ortiz-Ortiz, L. F. Bojalil, V. Yakoleff (eds) Biological, biochemical and 
biomedical aspects of actinomycetes. Academic Press, Orlando, pp 485-504

Stralka KA, Camper ND (1981) Microbial degradation of Profluralin. Soil Biol Biochem 13:33-38

Tewfik MS, Hamdi YA (1975) Metabolism of Trifluorodifen by soil microorganisms. Soil Biol Biochem 7:79-82

Thomson CL, Hill E, Epp JK, Probst GS (1983) The induction of bacterial mutation and hepatocyte unscheduled DNA synthesis by monosubstituted anilines. Environ Mutagen 5:803-811

Wang LH, Hamzah RY, Yu Y, Tu SC (1987) Pseudomonas cepacia 3-hydroxybenzoate-6-hydroxylase: induction, purification and characterization. Biochemistry 26:1099-1110
Whittaker JW, Lipscomb JD, Kent TA, Münck E (1984) Brevibacterium fuscum protokatechuate-3,4-dioxygenase: purification, crystallization and characterisation. J Biol Chem 259:4466-4475

Williams PP (1977) Metabolism of synthetic organic pesticides by anaerobic microorganisms. Residue Rev 66:63-123

Wolfrum G (1979) Other fluorine-containing dyes. In: Bank RE (ed) Organofluorine chemicals and their industrial applications. Society of Chemical Industry, Ellis Horwood Series in Industrial Chemistry, Ellis Horwood, Chichester, pp 208-213

Zeyer J, Kearney PC (1983) Microbial dealkylation of trifluralin in pure cultures. Pestic Biochem Physiol 20:10-18 